\title{
DE NUEVO SOBRE LA APÓCOPE VOCÁLICA EN CASTELLANO MEDIEVAL
}

La aparición de la Fazienda de Ultramar en $1965^{1}$, la publicación del Evangelio de San Mateo ${ }^{2}$ y el resto del Nuevo Testamento según la Biblia escurialense 1-1-6 ${ }^{3}$, estudios hechos por alumnos míos sobre el lenguaje de la Fazienda ${ }^{4}$, del Lapidario alfonsí ${ }^{5}$ y de otras partes de la misma Biblia ${ }^{6}$, y finalmente, objeciones reiteradas por Diego Catalán ${ }^{7}$, me obligan a reconsiderar la explicación que di hace veinticinco años a la apócope de la vocal en castellano antiguo ${ }^{8}$.

Mi explicación distinguía la apócope de la /-e/tras $r, s, l, n, z$ y $d$, normal y consolidada, de la apócope extrema que desde fines del siglo XI hasta mediar el xIV se dio tras otras consonantes (nuef, quicab, dix, noch, axac) y tras grupos de líquida o nasal + dental

1 La Fazienda de Ultramar. Biblia romanceada et itinéraire biblique en prose castillane $d u$ xii siécle. Introd., édition, notes et glossaire par Moshé Lazar, Salamanca, 1965. ( $A C S, 18,2)$. [E] texto romanceado no parece del siglo $\mathrm{xn}$, sino del primer tercio del xIII].

2 El Evangelio de San Mateo, según el $m s$. escurialense $I-I-6$, ed. de Thomas Montgomery, Madrid, 1962. (Anejos, BRAE, 7.)

3 El Nuevo Testamento según el ms. escurialense I-I-6, ed. y estudio de Thomas Montgomery y S. W. Baldwin, Madrid, 1970. (Anejos, BRAE, 22.)

4 María del Carmen Sanchis Calvo, El lenguaje de la $F$. de $U$. [memoria de licenciatura, Universidad Complutense de Madrid, 1970] (inédita).

5 Sagrario Rodríguez Montalvo, La apócope extrema de la vocal en el "Lapidario" de Alfonso X [memoria de licenciatura, 1964]; y El "Lapidario" de Alfonso X. Vocabulario [tesis, doctoral, Universidad Complutense de Madrid, 1970] (inéditas).

6 Jesús Moreno Bernal, Estudio lingüistico del ms. escurialense I-I-6. Biblia romanceada de la primera mitad del siglo xiii [tesis doctoral, Universidad Complutense de Madrid, 1975]. La citaré comó "Biblia" simplemente.

7 "En torno a la estructura silábica del español de ayer y del español de mañana”, $H H M, 77-110$, Current trends in linguistics, t. 9, The Hague, 1972, p. 1028 y Lingüistica ibero-románica. Critica retrospectiva, Madrid, 1974, p. 198, nota 541 .

8 "La apócope de la vocal en castellano antiguo. Intento de explicación histórica”, EMP, 2, 185-226. Lo citaré en adelante como Apócope. 
(adelant, part, fizist, ond, estonz). Igualmente consideraba normal la caída de / -o/ final en posición enclítica o proclítica si dejaba como remate de la palabra una de las consonantes no agrupadas que la fonología castellana ha tolerado allí en todo tiempo (Martino Gonsálvez > Martin Gongcalvez, solo > sol); y clasiticaba como extrema la que convertía en finales otras consonantes simples o grupos consonánticos (todo $>$ tot, Lobo $>$ Lop, Diago $>$ Diag, Diac, Fernando $>$ Fernand, Fernant, como $>$ com, etc.). La apócope normal, superado ei período inicial de contienda con el mantenimiento de la vocal final latina (honore, mese, tale, pane, faze, verdade), ha perdurado hasta nuestros días sin más retroceso que el impuesto por la analogía en la conjugación (eliminación de él quier, tien, sal, pued, yo quis, pud, fiz, etc., en beneficio de la regularidad representada por él quiere, tiene, sale, puede, yo quise, pude, fize $>$ hice). En cambio la apócope extrema surgió por prociisis o enclisis y empezó a propagarse a otros casos al tiempo que la caída de vocales intertónicas permitían que quedaran como finales de sílaba consonantes y grupos que antes no lo eran (limde, semdero, trepde, reptar, setmana, antparar, *vendgar, sangne); se extendió con auge notabilísimo como consecuencia del infiujo demográfico y cultural ultrapirenaico, especiaimente del Mediodía francés, desde fines del siglo xı hasta los primeros decenios del xıII; empezó a decaer conforme los hijos y nietos de "francos" afincados en Castilla y León se fueron incorporando plenamente al ambiente español y a su fonología, a la vez que aminoraba la inmigración y descendía su prestigio; y recibió un golpe definitivo cuando los esfuerzos de Aifonso X para combatirla obtuvieron como resultado póstumo excluir del modelo de buen lenguaje los finales consonánticos duros ${ }^{9}$.

$\mathrm{Al}$ dobie juego de causas intralingüísticas y externas que yo supuse cabe, desde luego, oponer una pregunta: si las condiciones internas, si la evolución misma del sistema fonológico castellano bastan para explicar la aparición de la apócope extrema ¿a qué invocar también factores extralingüísticos como la inmigración "franca" de los siglos xı y xir, a pesar de que sea innegable su huella en la vida y sociedad hispanas? Diego Catalán hace suya la relación que yo señalé entre el nacimiento de la apócope y la formación de grupos romances con final silábico duro, y la compieta relacionando igualmente la eliminación de la apócope extrema con la progresiva resolución de los grupos interiores donde las codas silábicas duras desaparecieron. Para Catalán la suerte de los finales de sílaba es la misma en el interior y en el final de las palabras:

- Denominaré así, para comodidad de la exposición, los finales conso. nánticos que no sean $r, s, l, n, z$ y $d$ no agrupadas con conconante previa. 
obedece a los cambios que la estructura silábica del idioma experimentó a lo largo de su evolución; y consecuentemente concluye: "Aunque los francos [...] contribuirían, sin duda, a difundir la apócope de la vocal final, no creo que haya que atribuir a su prestigio el arraigo de la apócope en la lengua hablada de Aragón, Castilla y León durante los siglos $\mathrm{xn}, \mathrm{xm}$ y xıv, según piensa Lapesa [...]. No veo, por tanto, razón alguna para seguir considerando a la "apócope extrema" como extraña al genio del idioma. De otra parte, la geografía del fenómeno favorece el carácter autóctono que creemos que hay que conceder a la apócope, pues su intensidad disminuye gradualmente según pasamos del catalán al aragonés, dei aragonés al castellano, del castellano al leonés y del leonés al gallego-portugués" ${ }^{10}$.

Nunca sentí dudas respecto al carácter autóctono de la apócope extrema en sus orígenes: fui el primero en relacionarla con la aparición de consonantes y grupos interiores implosivos, inusitados antes en la coda silábica, al caer las vocales intertómicas, tanto en interior de palabra como en el final de elementos proclíticos o enclíticos (Apócope, 193-195). Confieso haber sentıdo la tentación de relacionar asimismo la acomodación o eliminación de tales consonantes y grupos interiores con la decadencia y extinción de la apócope extrema; incluso lo hice en aiguna exposición oral. Pero siempre con cautela, porque advertí, tanto en el orto de ios dos fenómenos como en su menguante, desacuerdos que después haré notar, y porque vi en la apócope extrema anormalidades que las consideraciones intralingüísticas no llegaban a resolver. Son las siguientes: 1) la notable virulencia que muestra en el siglo xn y primera mitad del $\mathrm{xm} ; 2$ el contraste que durante la época alfonsí ofrecen textos coincidentes en fecha, pero contrarios en preferencias respecto a los finales de palabra, y 3) la rápida exclusión de la apócope extrema después de Alfonso X. Todo ello me obligó a sostener que el fenómeno originalmente autóctono se vio favorecido por factores de acción transitoria. Sería inexacto hablar de simple "moda", porque en la moda hay una dosis de frivolidad que no parece imputable a los clérigos medievales, principales agentes de la lengua escrita. Preferí y sigo prefiriendo ver en la apócope extrema el síntoma lingüístico de una crisis social y cultural, la que rompió la incomunicación de la España anterior al siglo xı con Europa, transformándola en la España europeizante -románica y gótica- de los siglos xn y xm, para desembocar en la del xıv, a la vez gótica y mudéjar, europea y peculiar. A continuación intentaré justificar esta postura.

Nuevas razones que abonan el origen autóctono de la apócope

10 "En torno a la estructura silábica", p. 79, nota 4. 
extrema-Los estudios de Sagrario Rodríguez Montalvo sobre el Lapidario alfonsí y de Jesús Moreno Bernal sobre la Biblia romanceada escurialense I-I-6 coinciden en señalar a la apócope extrema cicrtos condicionamientos: ocurre principalmente en final de grupo fónico, ya sea ante pausa final de frase, ya ante pausa interior. Dentro de la frase abunda ante vocal, mientras las formas plenas dominan ante consonante. Si la consonante que precede a la $-e$ final de palabra es igual o afín a la que inicia la palabra siguiente, la apócope es más rara ${ }^{11}$. Esta acción de las circunstancias fonéticas contextuales no se da en algunos otros textos, ni a rajatabla en el Lapidario y la Biblia; de todos modos es explicable en un fenómeno desarrollado orgánicamente, pero no lo sería si nos encontráramos ante el trasplante de una práctica surgida en otra lengua sin tales preferencias y rechazos.

El ensordecimiento de la consonante que, como consecuencia de la apócope, quedaba en posición final de palabra se produjo en castellano sin correspondencia exacta con ninguno de los romances cuyo influjo podría suponerse: en francés hay $/-\mathrm{v} />/-\mathrm{f} /$ (neuf, vif) $\mathrm{y} /-\mathrm{b} />/-\mathrm{p} /($ loup), pero no $/ \mathrm{-g} />/-\mathrm{k} /$ (ami, no amic) ni $/-\mathrm{d} /$ $>/-\mathrm{t} /$ (vertu, volonté), y la /-e/ impide el ensordecimiento de $/-\check{z}-/$ en $/ \check{s} /($ message, voyage $)$. El occitano desconoce también este resultado $/-\mathrm{s} /$ (messatge, viatge), y aunque ensordece $/-\mathrm{b} />/-\mathrm{p} /$, $/-\mathrm{d} />/-\mathrm{t} /$ y $/-\mathrm{g}>/-\mathrm{k} /$ (lop, voluntat, amic), vocaliza $/-\mathrm{v} />/-\mathrm{u} /$ (nou, viu) y reduce $/-\mathrm{nt} / \mathrm{y} /-\mathrm{nd} / \mathrm{a} / \mathrm{n} /$ (cauzimen, gran). El catalán, que coincide con el occitano en las soluciones messatge, viatge, llop, voluntat, amic, nou, viu, ensordece $/ \breve{\mathrm{g}} /$ en $/ \hat{\mathrm{c}} /$ (puig $:=[$ puĉc]) y tardó más en simplificar $/-\mathrm{nt} />/-\mathrm{n} /$, reducción no operada en gran parte del dominio lingüístico catalán. El castellano, que ofrecía nuef, Lop, Diac, omenax, adelant, no coincidía en la totalidad de los casos con ninguno de estos romances hermanos suyos. Además el ensordecimiento no era forzoso en castellano y presentaba no pocos resultados vacilantes (niev, nief, niep; av, af, auf; Lob, Lop, prob < p rope; voluntad, verdat; ond, ont; grand, grant, etc.).

Motivaciones linguiisticas ajenas a la estructura de la silaba.-Los cambios en la estructura silábica no explican alguno de los condicionamientos que favorecen la apócope extrema en castellano, ni tampoco el ensordecimiento de la consonante final.

Como ya se ha dicho, la apócope extrema se da con preferencia ante pausa, ya sea final de frase, ya interior. No sabemos -habrá

11 En el Lapidario: aymante tira 3 veces / aymant tira 2; semeiante de 12 / semeiant de 2; arte de 18, parte de passim, etc. En la Biblia: "mete to pie", "mete to ombro", frente a "met rayzes", "met los", "met mientes"; "acorveste tos lomos", "leveste to pecado", "feziste tü", etc., frente a un 75\% de pretéritos con -st apocopado. 
que determinarlo- si se producía sólo al término de una rama de entonación descendente, donde hoy es bien perceptible la relajación y hasta el ensordeciminto de la vocal, o si se daba también cuando presumiblemente había anticadencia. De todos modos el hecho implica un cese de vibraciones glotales que, además de producir la pérdida de la vocal, afectaba a la sonoridad de la consonante que la precedía.

Acaso haya que partir también de la entonación y del reparto de energía fónica para explicar la especial frecuencia de la apócope extrema en el imperativo singular (recib, sub, sab, bef 'bebe', escriv, met, bat, tuell-tuel, com 'come', tem, prent, cox 'coge', etc., en la Biblia I.I.6; bef, com, fuy, prent, sub, en la Fazienda). La característica energía con que se pronuncia la sílaba radical del imperativo, su mayor altura melódica, pudieron concentrar en ella el esfuerzo glotal y articulatorio, agotando el que hacía falta para ejecutar la vocal de la sílaba siguiente. Por otra parte la apócope constituía un procedimiento para distinguir la persona tú del imperativo de la persona él del presente de indicativo. Como quiera que sea, hay en la apócope extrema factores ajenos a la estructura silábica.

El paralelo entre la apócope extrema y los grupos consonánticos romances ofrece significativos desajustes.-No todos los fonemas y grupos registrados como finales de palabra a causa de la apócope extrema se encuentran como finales de sílaba interior ni en conglomerados fonéticos-sintácticos de palabras. Así ocurre con la $/ \hat{c} /$ de lech, noch, much; con la /g/ o /k/ de Diag-Diac, y con los grupos /ns/ de Alfons, Orens, /rt/ de part, cort. En otros casos la correspondencia es excepcional o escasa: la /-f/ de af o auf, naf, nief, nuef, nuf, of, bef tiene solitario correlato interior en derivados de v i d u a (bifda, enbefdar de la Biblia) ; y la /̌s/ de dix, adux, cox, trax, en los poco frecuentes frexno, trexnar.

La cronología de los fonemas y grupos implosivos es distinta según estén en interior o en final de palabra. El grupo /-nt / + consonante (antparar, *antnado) se resolvió muy pronto (amparar, annado, alnado) en posición interior, mientras que en final de palabra perduró largamente, con ejemplos hasta muy avanzado el siglo xIV ${ }^{12}$. El paso de *astmar (<a e s t i m a r e) a asmar y de * mastcar (m a s $\mathrm{t}$ i c a $\mathrm{r}$ e) a mascar fue tan rápido que no dejó -que sepamos- testimonio escrito de su/-st-/ implosivo; en cambio est, huest, tomest, dixist aparecen profusamente hasta 1280 y con menos frecuencia hasta más tarde. En sentido inverso: riepto, reptar continuaban usándose en el siglo $\mathrm{xv}$, pero princep y Lop habían sucumbido mucho antes ante principe y Lope. La /b/o / / implosivas de recabdar, cobdo, más.

12 A pócope, 222. Me refiero, claro está, a Castilla. En Aragón duró mucho 
dubda, cibdad tenían mucho vigor en tiempo de Juan II y de los Reyes Católicos; su /-b/ era grata aún para Juan de Valdés hacia $1585 \%$, y los sefardíes de los Baicanes siguen empleando kovdo, hovdisia, kavdal, sivdad ${ }^{14}$; pero quiçab, sab, recib, nueb apenas subsisten o desaparecen por completo después de 1280.

Vemos, pues, que el habla y la escritura castellanas de la Edad Media trataron de distinto modo, en muchos casos, las codas silábicas duras según se hallaran en interior o final de palabra. Ello no obsta para reafirmar que la apócope extrema encontró un portillo abierto en la aparición de finales de sílaba interior duros como consecuencia de haber caído vocales intertónicas; pero impide ligar los dos fenómenos a una causa única.

Extranjerismo con final consonántico duro.-Junto a ejemplos castellanos de apócope Diego Catalán cita indiscriminadamente muchas voces de procedencia extranjera, carentes ya de vocal final en la forma con que penetraron en el castellano de los sigos XI al xiIr. A continuación agruparé con ellas otras de origen semítico, galicano o catalán que figuran en mi artículo de 1951, algunas de la Fazienda de Ultramar, de la Biblia I-I-6 y del Lapidario, y unas pocas de otros textos. No intento, ni mucho menos, hacer catálogos exhaustivos, sino reunir los vocablos de estas condiciones que encuentro más a mano, suficientes por su número para demostrar la importancia del elemento foráneo en el auge de la apócope extrema. Veámoslos a título de ejemplo:

\section{DE ORIGEN SEMÍTICO}

a) Arabismos incorporados al vocabulario general castellano que entonces conservaban su final etimológico, alterado más tarde por adición de una vocal paragógica o sustituyendo la consonante dura por otra tolerable después: albaroc, alcaet-alcayt, alcauet, algib, almartac 'almártaga', almutaceb, ataut, axeb-axep 'ajebe', azarnech 'azarnefe', azevuch, azeit, çabach-zebech 'azabache', mariahadaracmarjadrac (Apócope, 222), roe 'roque del ajedrez', xac 'jaque', zumag-zumak, etc.

b) Arabismos léxicos registrados en textos castellanos, pero que no pasaron al uso común. Me limitaré a algunos del Lapidario: açrob 'plomo', adehenich-dihenich 'jaspe', albot 'crisol', alferuzach-feurizach 'turquesa', baurac 'bórax', zamorat 'esmeralda'. Recuérdese la nutrida terminología árabe del Saber de astronomia alfonsi.

13 Diálogo de la lengua, ed. J. F. Montesinos, Madrid, 1928, p. 66. (Clis. cast., 86.)

14 I. S. RÉvarI, "Formation et évolution des parlers judéo-espagnols des Balkans", $I b$, 1961, ním. 6, p. 185. 
c) Antropónimos de origen árabe o hebreo documentados en personajes de la época: Aben Carim, Abenmahfot, Aben Zadoc, Ebb, Galeb, Halab-Halap-Falahp, Hareb, Jucep-Josep, Sebib, Tamem, Zac-Zach, etc. ${ }^{15}$.

d) Topónimos de origen árabe o presumiblemente afectados por la apócope árabe, que después han tomado vocal final o han modificado la consonante: Alcabdet 'Alcaudete', Arganz 'Argance', Borialcayat 'Bujalcayado', Guada xox 'Guadajoz', Hageg o̊gey] eğ] 'Agés', Mahamut 'Mahamud', Mirauet 'Miravete', Montfrag 'Monfragüe', Rut 'Rute' 16 .

\section{Catalanismos, occitanismos y francesismos}

a) Préstamos con apócope extrema incorporados al léxico general: alum 'alumbre', aprés, arciprest, ardiment, ardit, argent, arlot, aveniment, aymant 'imán', barnax, consentiment, convent, convit, cosiment, deleyt, desdein, domen, drugamant, duc, eleofant, entall, espirament, cstanfort, estang, esirument, flum, franc, gambax, gent 'gentil', gilarniment, linax, mast, -ment adverbial, orpiment, pleitplet, princep, relox, ribalt-ribal, sacerdot, senab, solaz, talant, tost, vinpiment, etc.

b) Vocabulario extranjerizante con apócope extrema documentado en textos castelianos o leoneses de la época y que no pasó al uso común: lofarenc 'lorenés', ultraporz ${ }^{17}$.

c) Formas catalanas, occitanas o francesas apocopadas que sustituyen accidentalmente a las correspondientes castellanas: caualcr, cristaller, draper, peleter, en los Documentos lingüisticos ${ }^{18}$; hom (Fuero de Avilés); parell, fiadors, conils, tallans (Fuero de Valfermoso de las Monjas) ${ }^{19}$; fil, orgul, leopart, agost (Fazienda de Ultramar); ponent, crepuiscol (Saber de Astronomía), etc.

d) Apócope extranjerizante de palabras indígenas que en el uso castellano mantuvieron siempre su vocal final: rancurós (Fuero de Avilés) ; car 'carro', dreich 'drecho, derecho', collaz (Fuero de Villavaruz ${ }^{20}$; desiert (Fazienda de Ultramar).

1 J R. Menéndfz Prdal, Documentos lingüísticos de Lspaña. T. 1, Reino de Castilla, Madrid, 1919, núms. 16, 23, 24, 195, 265-267, 272 y 345 . En adelante citaré como Doc. ling.

16 Ibid., núms. 149, 165, 257, 266, 327, 328, 340 y 345.

17 Ibid., núm. 154; ultra porz, Fuero de Oviedo (C. M. Vigil, Colección histórico-diplomática del Ayuntamiento de Oviedo, Oviedo, 1887, pp. 16, 55.

1 soc. ling., núms. 79, 211 y 372.

19 Los estudios en Asturiano y provenzal en el Fuero de Airlés, Salamanca, 1948, p. 29, y "Los provenzalismos del Fuero de Valfermoso de las Monjas", PhQ, 51 (1972), p. 55.

20 "Rasgos franceses y occitanos en el lenguaje del Fuero de Villavaruz de Rioseco (1181)", TLL, 11 (1973), p. 531. 
e) Antropónimos con final consonántico duro procedentes de Cataluña, Occitania o Francia del Norte y atestiguados en Castilla o León durante los siglos xn y xin: sin salir de los Documentos lingüisticos, Adam, Amigoth, Anric-Henric, Armengot, BernaldBernalt-Bernard, Caluet, Chamarach, Donat, Felip-Felipp, Florenz, Frederich, Gasend, Gilibert, Gualard, Guilot, Guillem, Guiralt, Guzbcrt, Huc, Lambert, Leonart, Lorent-Lorenz, Malric, Odoart, Perronet, Perroth. Ponz, Remont, Rinalt, Robert, Vicent-Bincent, Yolant y muchos otros.

f) Topónimos galicanizantes con final duro: Beart (Doc. ling., núm. 284); Damasc (Fazienda).

Todos estos catalanismos y extranjerisnos, tanto los pertenecientes al léxico cuanto los nombres propios, contribuían a formar cima propicio a los finales consonánticos duros. Es posible que los pretéritos dixe, aduxe alternaran en Castilla con dix, adux antes de que se introdujeran barnax, gambax. linax, relox; también cabe que Lobo y Diago hubieran empezado a sonar Lop, Diac ante patronímico cuando todavía no habían entrado en castellano los semíticos axep, Halap, Jucep, albaroc, Zac o los galorrománicos princep, Felip, duc, Ffederich. Pero no es admisible poner en duda que tales extranjerismos hacían más habituales para los oídos castellanos los fonemas $/ \check{s} / \mathrm{y} / \mathrm{k} /$ en final de palabra. Un ejemplo más, e ilustre: en la estrofa inicial de los Milagros Gonzalo de Berceo apocopa el cultismo omnipotent para que rime con los catalanes o provenzales seguros cosiment, aveniment, y con el muy probable vera ment.

Procedencia de los escribas.-Creo imprescindible tener en cuenta que no pocos textos con apócope extrema se deben a escribas de origen galorrománico o catalanes. Tuvieron que serlo los que se valieron de mezcolanzas lingüísticas como las del Fuero de Avilés hacia 1155 o la del apéndice al Fuero de Villavaruz de Campos en 1181 ; lo era, a juzgar por su nombre y su lenguaje, el "Ebrardus capellanus" que en 1189 transcribió el Fuero de Valfermoso de las Monjas, siendo abadesa del convento "doña Nóbila de Périgord". Hay que suponer gascón o catalán al autor del Auto de los Reyes Magos, donde riman escarn[o] y carn [e], fembra y december 21 . Sin hibidrismo semejante, la Fazienda de Ultramar, aparte de la ya mencionada apócope de orgul, leopart, fil, desiert, Damasc, Tyr, ofrece bastante intercambio entre $a$ y $e$ protónicas o finales (prandamos 62, saremos 69, tornerá 156, levera 162; pazarán 'pacerán' 164, ardarán 188, Vespesianus 203; Romelie 163, Sidonye 120, Galile 112, Ydumee 116, "Osee la propheta" 184); seseo (sierço

21 "Sobre el Auto de los Reyes Magos: sus rimas anómalas y el posible origen de su autor", Homenaje a Fritz Krüger, Mendoza, 1954, t. 2, pp. 591-599. 
12 , enzuzieste 59, sielo 206, services 210 , sera 'cera' 213) y otros rasgos que hacen pensar fuese gascón o catalán. Es muy probable el origen "franco" de Frey Bernard, monje de Fitero, que en 1212 autoriza en Cervera de Río Alhema una donación donde constan los nombres de don Espannol, Vincent, Be[r]tolomeu, don Maurin abbat", "Frey Arnalt", y se usan ensemble, conuent, present y part (5 veces), aunque también entegramientre y no -ment (Doc. ling., num. 113) . "Franco" u oriundo de francos debía de ser "Johannes Geraldi sacerdos", que en 1239 escribe en Carrión part (10 veces), adelant y muert ( 2 veces cada uno), omnipotent, "plenera mient", tenient, documento en que figuran "don Guilhem Gómez" y "don Bienuenist capellan" 22. Los notarios Jacme, Arnalt de Vallebrera y Bonduco Fores redactan escrituras murcianas de 1262, 1293 y 1305 respectivamente, en las que insertan catalanismos acordes con abundantes nombres propios de igual procedencia, y formas apocopadas dauant, end, cibdadant, recibient, guarent, present ${ }^{23}$.

Claro está que los escribas indígenas no podían menos de experimentar influjo favorable a la apócope cuando estaban rodeados de "francos": así ocurre hacia 1200, Burgos, a Juan de Riolacedo, que usa part en una escritura donde constan seis nombres y apellidos ultrapirenaicos (ibid., núm. 154); a Lope, escribano de las Huelgas, que entre 1220 y 1226 emplea puent, "ond son", "est camio", "part de forno", "suert de su madre", vacila entre "regnant el rey" y regnante, "ifant don AIfonso" e "yfante d.A." y hace constar siempre "Lop escriuió", en documentos donde se nombra a Pere Henric, Guiralt Aymar, Guillem de Bordel, Pere Lambert, don Perronet y don Maté del Chastel ${ }^{24}$; o a Johan Périz de Valgañón y Domingo de la Vid, escribanos públicos de Frías, que entre 1267 y 1278 estampan Enbith, fuent, Mirauech, y repetidamente "ant son", part, Sant Vicent, "delant los testigos" mont, teniendo como confirmantes o haciendo referencia a don Bernalt Remont, don Guiralt, Pero Caualler, don Belmont, etc.25.

Consideraciones semejantes hay que hacer respecto de los judíos, bilingües o trilingües en su gran mayoría. Acostumbrados a los finales duros, abundantes y normales tanto en hebreo como en árabe, es natural que los prefiriesen, o al menos no los evitasen, cuando hablaban castellano. A fines del siglo xn y comienzos del xiII documentos otorgados en la aljama de Aguilar de Campó ofrecen en su redacción fórmulas desconocidas en los hábitos notariales cristianos; junto a la era hispánica, dos de ellos fechan por el año

22 E. STAFF, Etude sur l'ancien dialecte léonais, Upsala, 1907, doc. XVIII.

z3 Doc. ling., núms. 365, 371 y 372 .

24 Ibid., núms. 167-169 y 172-175.

¿5 Ibid., núms. 60,62 y 64 . 
"quatro mil nueb cientos $e$ ojaenta" de la Creación; ese nueb está a tono con la /b/ implosiva interior de "bibda de Iuceph", resultante de la evolución espontánea que, a partir del latín v i d u a, llegaría con el tiempo al castellano moderno viuda; pero no es menos cierto que la $-b$ final de nueb concuerda con la de Halab y "Petro Stephonez $E b b$ ", individuos pertenecientes a la misma judería ${ }^{26}$. Cuando la apócope extrema se hallaba en notoria decadencia, repudiada por el uso general de letrados y próceres, don Sem Tob no sentía escrúpulos en valerse de "quem fizo", "por end", pryncep, "not fartas", $s a b$, etc.; las Coplas de Yocef muestran "et quiero defender". "dezirté kom farás", "alyám soterrarás" (Apócope, 223) ; todavía en 1920 el judeo-español marroquí de Xauen conservaba nief por 'nieve' (ibid., 224). No se debe olvidar el factor hebreo al estudiar la anócope de las biblias medievales y de las traducciones en que colaboraron judíos, castellanos y "francos". Aquellos y estos tenían hábitos !ingiísticos nativos que favorecían la opción por adelant, mont, hart. nueb o nuef, tot, etc. ¿Podrían los castellanos sustraer su e'ección entre formas plenas y apocopadas al doble inf!ujo de las gentes con quienes trabajaban en equipo?

Insisto en afirmar que los notarios, clérigos y juglares castellanos practicaban espontớneamente la apócope extrema, aunque no de modo sistemático. I o que creo también indudable es que la convivencia con francos y semitas hubo de ser propicia a los finales duros; en toda Castilla y gran parte de León hasta mediar el siglo xin; en las zonas castellanas del Norte y en las lindantes con Navarra y Aragón, hasta más tarde.

Lengua hablada y lengua escrita.-La apócope extrema nació en el habla del Centro peninsular, se incrementó en el habla y luego decayó en el habla hasta extinguirse. Ahora bien, creo necesario admitir que en la lengua escrita fue más arrebatado su crecimiento y más rápido su declive. Entre el habla y la escritura hubieron de existir diferencias cuyo signo fue distinto según los momentos. Si nos atuviéramos solo al testimonio de la Disínta del alma y el cuerpo y los documentos notariales de 1190 a 1230 , tendríamos que dar por sentenciado el pleito a favor de la apócope extrema, usada exclusivamente o con preferencia muy superior a la de las formas plenas. Pero estas debian de poseer en el habla mucho más vigor del que reflejan los textos escritos: de otro modo no habría sido posible la reacción que siguió. A fines del siglo xiII se produjo un despegue inverso: cuando la tendencia favorable a las formas plenas desterró de la escritura culta y señorial los fina. les de palabras duros, el coloquio popular y la literatura que lo representaba - el Libro de buen amor- los conservó decadentes

26 Ibid., núms. 16, 23 y 24, años 1187,1219 y 1220. 
hasta medio siglo más tarde, antes de que hallaran su último refugio en el ambiente marginal de las aljamas.

En último término se trata de cambios en el modelo de lenguaje. Entre 1100 y 1250 clérigos, juglares y notarios crearon y mantuvieron un nivel de lengua escrita donde prevalecía la apócope extrema por ser rasgo en que los castellanos y leoneses podían coincidir con los "francos", que significaban el lazo de unión a la Europa cristiana, y con los judíos, que trasvasaban al mundo occidental la cultura árabe, heredera de la griega e india. Pero el creciente uso escrito del romance a costa del latín originó en aquel mayor conciencia gramatical, propulsora de que cada palabra mantuviese identidad formal consigo misma en los distintos contextos donde pudiera aparecer. Los plurales, que conservaban la vocal final y no alteraban la consonante que la precedía, actuaron sobre los singulares restringiendo la apócope de una y el frecuente ensordecimiento de la otra. Por otra parte esta regularidad satisfacía el independentismo lingüístico de quienes sentían ya oneroso el influjo "franco", antaño gratamente aceptado. La reacción, leve durante el reinado de Fernando III, provocó en el de Alfonso X la lucha entre las dos corrientes. Así pudieron coincidir cronológicamente la mucha apócope que hay en el fuero de Santo Domingo de la Calzada otorgado por el rey en 1255 y escrito por Millán Pérez de Aillón ${ }^{2 \tau}$, y la inexistente en el códice regio de la Partida $I$, cuyo prólogo, debido al monarca, nunca omite la vocal final (ende, ante, este, -mientre), y en cuyo texto solo apocopan grand o grant, precediendo a sustantivo, y la preposición segunt (ibid., pp. 214219). No repetiré ahora la mención de otros contrastes semejantes que señalé en la obra alfonsí hace un cuarto de siglo (Apócope, 217221). Recordaré el muy significativo que se da entre la señorial y meditada prosa de don Juan Manuel, carente de apócope extrema, y las estrofas, popularistas y vivaces, de Juan Ruiz, que todavía conservan alguna (ibid., 222-223). Esa contraposición confirma el carácter sociocultural de los cambios lingüísticos que nos ocupan. La apócope extrema desapareció al triunfar la nueva norma, asentada por una minoría rectora, mucho antes que no pocos finales duros dejasen de existir en sílabas interiores. $*$

RAFAEL LAPESA

Real Academia Española.

Universidad Complutense, Madrid.

27 R. Menínde Pidal, Grestomatia del español medieval, Madrid, 1965, t. 1, pp. 259-262. 